\title{
Jenseits von Europa
}

Neulich in den Fernsehnachrichten: In Simbabwe wirft die Opposition der Regierung Wahlbetrug vor. Simbabwe - was weiss ich eigentlich über dieses Land und seine Bewohner? Natürlich, der Infektiologe Ruedi Lüthy hat dort in Harare eine HIV-Klinik initiiert und wurde für sein Engagement mit der Auszeichnung «Europäer des Jahres 2007» geehrt. Doch damit bin ich im Stil eines kunstvoll geschleuderten Bumerangs bereits wieder in unseren Breiten gelandet.

Neuer Anlauf: In Henning Mankells beeindruckendem Afrika-Roman «Das Auge des Leoparden» sprechen weisse Farmer im von Unruhen heimgesuchten Sambia mehrfach davon, nach Rhodesien auszuwandern. Das heutige Simbabwe gilt ihnen gewissermassen als das gelobte Land. Doch das sind tempi passati, soviel hat man auch als durchschnittlich informierter Mitteleuropäer mitbekommen. Ein diktatorisches Regime, eine gescheiterte Landreform und gewaltsame Enteignungen liessen den einstigen Musterstaat im südlichen Afrika in eine tiefe Krise schlittern. Was man in den Reportagen am Fernsehen vor allem gesehen hat - oder woran ich mich am besten erinnere -, war die Tragik der enteigneten weissen Landbesitzer.

Doch liegt da nicht seit einigen Wochen dieses Bändchen mit orangerotem Umschlag auf meinem Pult, ein unaufgefordert zugestelltes Rezensionsexemplar, das beim ersten Durchblättern mein Interesse weckte, so dass ich es mir für eine vertiefte Lektüre und allfällige Besprechung aufhob? «Sie tragen die Welt auf dem Kopf»* heisst das Buch der Theologin und Journalistin Katharina Morello, die mit ihrem Mann - er arbeitete als Arzt in einem Landspital - und ihren zunächst zwei, später drei Kindern ein Jahr in Simbabwe verbrachte. Diesmal fliegt der Bumerang nicht mehr zurück - ich bin angekommen.

Zum Beispiel bei der «Unternehmerin» Mai Jenica. Sie bringt das Kunststück zustande, auf der Basis eines geschenkten Plastiksacks voller bunter Haarklammern eine hochrentable Hühnerzucht zu etablieren. Beziehungen zum Management eines regionalen Supermarktes werden geknüpft, frau investiert: Mai Jenica wird Besitzerin der einzigen erschwinglichen Kühltruhe in der Region. Und siehe da: Auch ihr ExMann meldet sich wieder. «Sie sei die tüchtigste

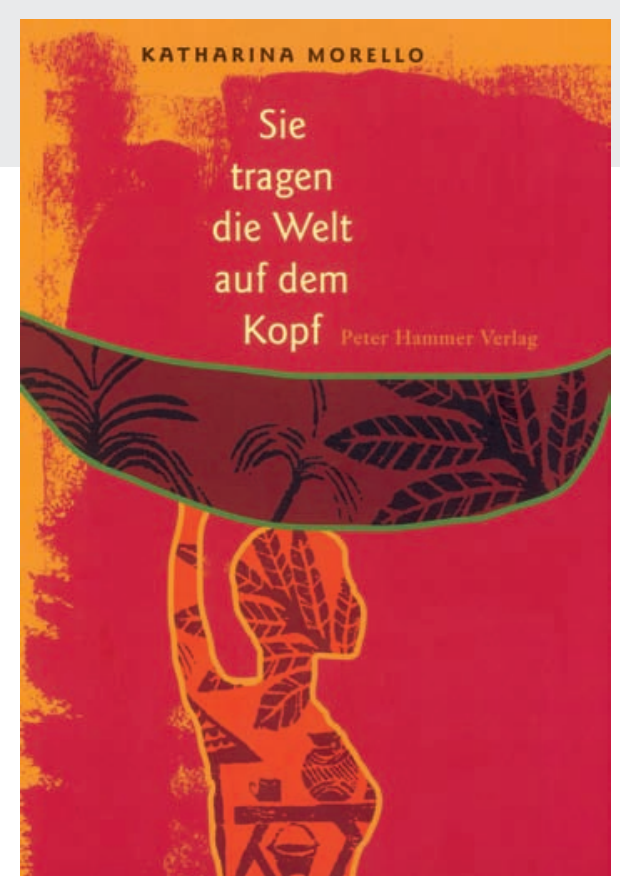

aller Frauen, lässt er ausrichten. Wenn sie zurückkäme, würde sie es gut haben bei ihm.» Das allerdings tut sie sich nicht mehr an, denn wahrscheinlich ist es eher umgekehrt gemeint. Und auch durch das Damoklesschwert der Inflation, das als permanente Bedrohung über der Unternehmerin schwebt, lassen sich Frauen wie sie nicht unterkriegen: «[...] sie haben Ideen. Sie finden Neues.»

Morello liefert keine distanzierte soziologische Analyse der Zustände in Simbabwe. Sie muss sich auch nicht primär als Journalistin unters Volk mischen, um zu ihren Geschichten zu kommen. Als «Arztfrau» - als die sie offenbar in der Region bekannt ist - steht sie in regem Kontakt mit den Einheimischen, insbesondere mit den Frauen, die mit ihren alläglichen Freuden und Problemen im Zentrum der 26 Miniaturen stehen. In diesem Kaleidoskop des täglichen Lebens ist die politisch-wirtschaftliche Lage zwar notwendigerweise und durchaus prägend präsent, nie aber in aufdringlicher Form: Sie erscheint eher wie eine allgegenwärtige Landschaftssilhouette im Hintergrund.

In einer wohltuend unaufgeregten, stellenweise fast lakonischen, immer aber sorgfältigen Sprache bringt uns Morello den Mikrokosmos des ländlichen Simbabwe nahe. Mit Empathie und Sinn für die Komik des Alltags findet sie Zugang zu einer fremden Welt und deren geduldigen, phantasie- und humorvollen Bewohnern. Einer Welt, die die Frauen auf dem Kopf tragen.

Bruno Kesseli
Welt auf dem Kopf. Wuppertal: Peter Hammer; 2008. 150 Seiten. Fr. 29.-. ISBN 978-3-7795-0176-3. 